\title{
Pengelolaan Metode Pembelajaran dengan Memanfaatkan Museum Pada Pembelajaran Sejarah Bagi Guru SMA Muhammadiyah Makasar
}

\author{
Merina $^{1^{*}}$ dan Daniel Fernandez ${ }^{2}$ \\ ${ }^{1}$ Fakultas Keguruan dan Ilmu Pendidikan, Universitas Muhammadiyah Prof. Dr. Hamka, Jakarta, Indonesia \\ ${ }^{2}$ Fakultas Ilmu Sosial dan Ilmu Politik, Universitas Muhammadiyah Prof. Dr. Hamka, Jakarta, Indonesia \\ *Email korespondensi: merina@uhamka.ac.id
}

\begin{abstract}
Abstrak
Keberadaan museum merupakan bentuk representatif sebuah kota. Sekolah yang dikeliling berbagai macam museum seperti SMA UNISMU 1 Makasar memiliki kesempatan besar untuk menjadikan museum sebagai alternatif proses pelaksanaan pembelajaran sejarah. Sebuah kunjungan ke situs sejarah juga dapat membantu siswa memahami situasi kejiwaan yang terjadi di kala itu. Pola pembelajaran sejarah dengan observasi langsung ke berbagai situs sejarah dapat memberikan pengalaman yang lebih bermakna dari pada sekedar belajar dengan cara menghafal. Pengembangan metode pembelajaran sejarah yang dapat dicoba dan diterapkan adalah kunjungan ke museum. Guru sejarah di SMA UNISMU 1 Makasar sudah sepantasnya mendapatkan pelatihan mengenai metode pembelajaran ini. Pelatihan pengembangan metode melalui kunjungan museum dilakukan dengan beberapa tahap, yaitu mulai dari perancangan model, pemilihan media dan bahan ajar dan simulasi kegiatan.
\end{abstract}

Kata kunci: metode, pembelajaran, museum, sejarah

\begin{abstract}
The museum existence is a representative form of city. The school that is surrounded by various museums such as SMA UNISMU 1 Makasar has a great opportunity to make the museum as an alternative process of history learning implementation. A visit to a historical site can also help students to understand the psychological situation that occurred at that time. Historical learning patterns with direct observation to various historical sites can provide a more meaningful experience than just learning by memorization. The development of historical learning methods that can be tried and implemented is a visit to the museum. The history teacher at SMA UNISMU Makasar deserves training on this learning method. The training of method development through museum visits was carried out in several stages, ranging from model design, selection of media and teaching materials and simulation activities.
\end{abstract}

Keywords: method, learning, museum, history

Format Sitasi: Merina \& Fernandez, D. (2018). Pengelolaan Metode Pembelajaran dengan Memanfaatkan Museum pada Pembelajaran Sejarah bagi Guru SMA Muhammadiyah Makasar. Jurnal SOLMA, 7(2): 258-265. Doi: http://dx.doi.org/10.29405/solma.v7i2.2235

Diterima: 1 Oktober 2018 | Revisi: 15 Oktober 2018 | Dipublikasikan: 30 Oktober 2018.

\section{PENDAHULUAN}

Keberadaan museum merupakan bentuk representative sebuah kota. Selain itu museum juga merupakan tempat bersejarah dan tempat menyimpan benda-benda yang yang dapat dimanfaatkan untuk pembelajaran sejarah bagi siswa (Kushardjanto, 2015). SMA 
UNISMU Makasar merupakan sekolah yang dikeliling berbagai macam museum. Hal ini dapat menjadi alternatif proses pelaksanaan pembelajaran sejarah. Selain itu kunjungan ke situs sejarah juga dapat membantu siswa menyerap situasi kejiwaan yang terjadi di kala itu (Hartono, 2001). Pola pembelajaran sejarah dengan observasi langsung ke berbagai situs sejarah dapat memberikan pengalaman yang lebih bermakna dari pada sekedar belajar dengan cara menghafal.

Penerapan metode baru dalam pembelajaran sejarah sudah syogyanya dilakukan karena selama ini pembelajaran monoton dengan ceramah yang membuat siswa menjadi jenuh. Pengembangan metode pembelajaran sejarah adalah satu metode yang dapat dicoba dan diterapkan (Irdana \& Kumarawarman, 2018). Guru sejarah di Makasar sudah sepantasnya mendapatkan pelatihan mengenai metode pembelajaran ini.

\section{MASALAH}

Sekolah SMA UNISMU 1 Makassar mengalami masalah terkait dengan pelaksanaan pembelajaran yang cenderung menghafal.. Pada pembelajaran sejarah, guruguru di sekolah tersebut merasa siswa mereka cerdas secara kognitif dimana mereka mampu mengingat pristiwa sejarah pada beberapa materi namun tidak dapat memahami betul peristiwa sejarah yang terjadi. Bukti nilai ulangan harian siswa dapat dikategorikan baik namun siswa cepat lupa dan tidak memahami betul peristiwa sejarah yang terjadi.

Disisi lain mereka memiliki permasalahan yaitu ketika proses pembelajaran berlangsung, hampir $70 \%$ siswa merasa sangat bosan. Hal itu terlihat dari raut muka yang tidak antusias dan minimnya interaksi. Siswa juga tidak antusias dalam mengerjakan tugas yang diberikan. Salah satu cara untuk membangkitkan kesadaran sejarah yang dapat dilakukan oleh guru adalah dengan memberikan pembelajaran kontekstual (Syafii, 2014). Fasilitas museum menjadi lokasi yang tepat sebagai sumber belajar pembelajaran (Nugroho \& Meriza, 2016; Syafii, 2014). Guru tentu memiliki kesulitan ketika mereka menerapkan metode pembelajaran dimana museum sebagai lokasinya. Hasil survei menyatakan bahwa guru-guru sekolah memiliki pemahamaan yang masih rendah terkait museum sebagai alternatif pelaksanaan pembelajaran sejarah. Pemahaman mereka masih rata rata pada skor 45 dengan skor tertinggi 100.

Berdasarkan pemaparan diatas maka masalah yang dihadapi mitra yang perlu diselesaikan adalah:

a) Siswa mengalami kebosanan dalam belajar sejarah.

b) Pemahaman guru mengenai pengembangan metode. 
c) Guru membutuhkan pelatihan terhadap penerapan pembelajaran sejarah di musem.

\section{METODE PELAKSANAAN}

Pendekatan yang digunakan pada kegiatan pengabdian ini adalah workshop dan praktik. Workhsop dilakukan di labolatorium IPS sekolah selama satu hari. Laboratorium IPS merupakan representatif dari miniature museum, di mana di dalamnya terdapat replica benda-benda bersejarah. Pada kegiatan ini dipaparkan materi dan simulasi. Hal ini bertujuan agar peserta memahami secara langsung penerapan metode pembelajaran di museum. Praktik dilaksanakan dengan kunjungan ke museum. Hal ini bermanfaat supaya dari hasil teoritik peserta langsung mencobakan dalam situasi yang nyata.

\section{a. Rencana Kegiatan}

Kegiatan pengabdian ini dilakukan dalam empat tahap. Masing-masing tahap merupakan bagian yang saling terkait.

1) Tahap Persiapan

Tahap persiapan dilaksanakan dengan cara mengirim surat ijin dari sekolah agar gurunya terlibat dalam pelaksanaan kegiatan. Selain itu sosialisasi ke mahasiswa yang akan terlibat dalam kegitan ini.

2) Tahap Workshop

Tahap ini berupa kegiatan workshop. Kegiatan ini dilaksanakan dalam satu hari. Kegiatan workshop ini berisikan paparan materi dan simulasi.

3) Tahap Praktik

Tahap inti, yaitu kunjungan ke museum yang menjadi lokasi atau konteks pembelajaran.

4) Tahap Evaluasi

Tahap evaluasi merupakan tahap merefleksi kegiatan pengabdian yang telah dilakasanakan.

\section{b. Partisipasi Mitra dalam Program}

Pelaksanaan kegiatan pengabdian memerlukan partisipasi mitra. Mitra kegiatan pengabdian ini berperan sebagai berikut:

(1) Mitra guru-guru akan berpartisipasi menjadi peserta program ini.

(2) Guru membantu mensosialisasikan metode kunjungan museum sebagai salah satu alternatif pelaksanaan pemebelajaran sejarah yang berbasis Contextual Teaching and Learning (CTL). 


\section{PEMBAHASAN}

Pengembangan metode melalui kunjungan museum dilakukan dengan beberapa tahap. Tahap pertama pra pelaksanaan dan tahap pelaksanaan. Pada tahap pra pelaksanaan, tim mulai dengan melakukan proses identifikasi keadaan siswa sekolah yang menjadi mitra pada pelaksanaan pengabdian ini dibantu oleh guru mata pelajaran sejarah. Setelah itu tim merancang model yang akan digunakan. Proses perancangan model diawali dengan merumuskan rencana pembelajaran dengan melihat standar kopetensi, kompetensi inti serta tujuan pembelajaran. Setelah itu diikuti dengan pemilihan media serta bahan ajar pendukung yang akan digunakan dalam proses pembelajaran di museum. Setelah melakukan proses perencanaan, maka pengembang melakukan tahap rancangan dengan membuat media serta bahan ajar pendukung. Kegiatan pengabdian ini menghasilkan produk berupa strategi pengembangan yang dapat dilihat pada Tabel 1.

Tabel 1. Produk Strategi Pengembangan Pembelajaran di Museum

\begin{tabular}{|c|c|c|c|}
\hline Tahap & Ketegori Kompetensi & $\begin{array}{c}\text { Dimensi } \\
\text { Pengetahuan }\end{array}$ & Media \\
\hline - Konstruktivis & $\begin{array}{l}\text { - Berkomunikasi lisan } \\
\text { - Berekspresi verbal } \\
\text { - Potensi auditif } \\
\text { - Berpikir dalam } \\
\text { kata secara } \\
\text { original } \\
\text { - Memory repropktif } \\
\text { ke produktif }\end{array}$ & $\begin{array}{l}\text { - Pengetahuan fakta } \\
\text { (what) } \\
\text { - Pengetahuan } \\
\text { konseptual (what) } \\
\text { - Meta kognitif }\end{array}$ & $\begin{array}{l}\text { - Lembar } \\
\text { Observasi } \\
\text { - Benda koleksi } \\
\text { Museum } \\
\text { - Film } \\
\text { Dokumenter }\end{array}$ \\
\hline - Tanya Jawab & $\begin{array}{l}\text { - Berkomunikasi lisan } \\
\text { - Kemampuan berpikir } \\
\text { logis } \\
\text { - Berpikir kritis } \\
\text { - Kemampuan analitis } \\
\text { - Berpikir kreatif }\end{array}$ & $\begin{array}{l}\text { - Pengetahuan fakta } \\
\text { - Pengetahuan } \\
\text { konseptual } \\
\text { - Prinsip dan } \\
\text { generalisasi }\end{array}$ & $\begin{array}{l}\text { - Benda koleksi } \\
\text { Museum }\end{array}$ \\
\hline - Inkuiri & $\begin{array}{l}\text { - Berkomunikasi lisan } \\
\text { - Berpikir dan } \\
\text { Berekspresi visual } \\
\text { - Berimajinasi visual } \\
\text { - Kematangan } \\
\text { emosional }\end{array}$ & 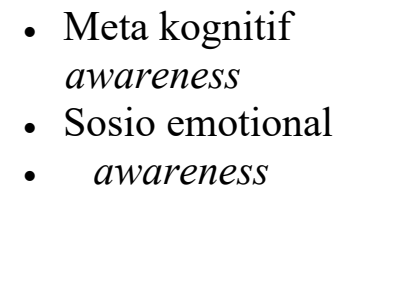 & $\begin{array}{l}\text { - Benda koleksi } \\
\text { Museum } \\
\text { - Artikel } \\
\text { - Lembar Studi } \\
\text { kasus dan } \\
\text { permasalahan }\end{array}$ \\
\hline - Refleksi & $\begin{array}{l}\text { - Berpikir dan } \\
\text { berekspresi natural } \\
\text { - Berpikir dan } \\
\text { berekspresi visual } \\
\text { - Berimajinasi visual } \\
\text { - Kematangan } \\
\text { emosional }\end{array}$ & $\begin{array}{l}\text { - Meta kognitif } \\
\text { - Konseptual } \\
\text { - Teori, model, dan } \\
\text { struktur } \\
\text { - Pengetahuan } \\
\text { procedural }\end{array}$ & $\begin{array}{l}\text { - Draft umum } \\
\text { naskah drama } \\
\text { - Bendera merah } \\
\text { putih } \\
\text { - Musik dan lagu- } \\
\text { lagu nasional } \\
\text { - Kartu Soal } \\
\text { - Pertanyaan } \\
\end{array}$ \\
\hline
\end{tabular}




\begin{tabular}{|c|c|c|c|}
\hline $\begin{array}{l}\text { - Penilaian } \\
\text { Otentik }\end{array}$ & $\begin{array}{l}\text { - Berpikir dan } \\
\text { berekspresi natural } \\
\text { - Berpikir dan } \\
\text { berekspresi visual } \\
\text { - Berimajinasi visual } \\
\text { - Kematangan } \\
\text { emosional } \\
\text { - Kematangan sosio } \\
\text { emosional }\end{array}$ & $\begin{array}{l}\text { - Prosedural } \\
\text { knowledge } \\
\text { - Meta kognitif } \\
\text { awareness } \\
\text { - Sosio emotional } \\
\text { - awareness }\end{array}$ & $\begin{array}{l}\text { refleksi diri } \\
\text { - Lembar laporan } \\
\text { kunjungan } \\
\text { museum }\end{array}$ \\
\hline
\end{tabular}

Adapun simulasi pelaksanaan dalam proses pengembangan model pada tahap ini terbagi menjadi beberapa kegiatan, yaitu:

1. Pembagian Kelompok

Pada tahap ini, siswa yang berupa guru dibagi menjadi dua kelompok yaitu dengan nama kelompok Ahmad Soebardjo dan M. Yamin. Setelah pembagian kelompok oleh mentor siswa diajak perkenalan dengan melakukan simulasi permainan perkenalan nasionalisme yang bertujuan untuk memperoleh keakraban antara mentor dan siswa peserta kegiatan dan bertujuan menmberikan kontekstual sebagai tokoh-tokoh perumus kemerdekaan.

2. Pemaduan

Pada tahap ini mentor memaparkan materi sesuai dengan indikator di dalam RPP (Rencana Pelaksanaan Pembelajaran) dan silabus. Paparan materi dilakukan dengan mengajak siswa peserta kegiatan yang terdapat pada display yang dipamerkan museum. Selain itu pada proses ini siswa bukan hanya mendengarkan paparan materi dari mentor akan tetapi terjadi pula proses tanya jawab dari mentor dan pertanyaan yang terdapat pada modul serta permainan kecil dan pemberian apresiasi terhadap siswa yang berhasil menjawab.

\section{Menonton Film Dokumenter}

Pada tahap ini, siswa peserta kegiatan dipandu memasuki teater mini yang terdapat di museum untuk menonton tayangan film dokumenter seputar perumusan kemerdekaan hingga kemerdekaan. Pada tahapan ini pula siswa dengan tertib menonton tayangan dan setelah itu mentor memberikan refleksi dari hasil tayangan kepada siswa peserta kegiatan. 


\section{Ice Breaking dan Kegiatan Gali Potensi}

Pada tahap ini semua kelompok di kumpulkan dan melakukan kegiatan ice breaking yang dipandu oleh mentor dan memberikan penugasan kepada masing-masing kelompok yang terdapat di dalam modul pada setiap materinya.

5. Evaluasi Pembelajaran

Pada tahap ini dilakukan evaluasi pembelajaran dengan tujuan mengetahui seberapa besar pemahaman siswa peserta kegiatan terhadap materi yang disampaikan dalam pembelajaran melalui model CTL. Evaluasi dilakukan dengan melakukan, yaitu:

\section{a) Mencari Harta Karun (Kartu Soal)}

Pada kegiatan ini, mentor menyiapkan dua buah kartu soal untuk dua kelompok yang disimpan di tempat yang tidak diketahui oleh semua kelompok. Setelah mentor menjelaskan aturan main kegiatan tersebut, semua kelompok mencari kartu soal tersebut dan menjawab soal dengan mencari jawaban pada display yang dipamerkan museum maupun film yang telah ditayangkan pada tahap sebelumnya. Setiap kelompok yang sudah berhasil mendapatkan jawaban dan menuliskannya di lembar jawaban maka kelompok tersebut harus mendatangi mentor yang bertugas memeriksa lembaran jawaban maupun mendengarkan paparan jawaban tersebut secara lisan. Setelah jawaban dianggap benar maka kelompok tersebut dapat mencari hadiah di tempat yang tidak diketahui oleh semua kelompok sebagai bentuk apresiasi.

b) Komunikata

Pada kegiatan ini semua kelompok menempati posisi duduk berbanjar, kemudian siswa yang berada pada barisan paling belakang diberikan beberapa kata lalu menyambungkannya menjadi sebuah pernyataan lalu memberikannya kepada teman did dalam kelompoknya, setelah itu siswa yang berada paling depan diminta untuk menyebutkan pernyataan dengan benar. Adapun kelompok yang menyebutkan pernyataan dengan benar akan diberikan apresiasi.

\section{c) Cerdas Cermat}

Pada kegiatan ini, evaluasi dilakukan dalam bentuk cerdas cermat. Adapun soal dibuat berdasarkan materi yang telah dipaparkan dalam kegiatan pemanduan. Kemudian mentor membacakan soal dan setiap kelompok harus menjawab pertanyaan tersebut dalam bentuk rebutan. Kelompok yang mendapatkan nilai tertinggi mendapatkan apresiasi di akhir kegiatan. 


\section{d) Mengerjakan Soal}

Pada Kegiatan ini setiap siswa mengerjakan soal yang terdapat pada modul, dan kemudian dikumpulkan kembali ke mentor untuk diperiksa jawabannya. Kegiatan ini dlakukan untuk mengetahui hasil belajar peserta didik.

\section{KESIMPULAN}

Berdasarkan dari pengamatan dan pelatihan yang dilakukan, guru SMA UNISMU 1 Makasar sangat antusias dalam mengikuti kegiatan. Simulasi metode yang ditawarkan sangat membantu guru dalam pengembangan metode pembelajaran sejarah dan dapat dijadikan alternatif metode pembelajaran ketika mengunjungi museum. Adapun pelatihan yang diterapkan dilakukan dengan berbagai kegiatan, diantaranya: 1) Pembagian kelompok, 2) Pemanduan, 3) Menonton film dokumenter, 4) Ice braking dan gali potensi, dan 5) Ragam Evaluasi.

\section{UCAPAN TERIMA KASIH}

Terima kasih diucapkan kepada:

1. Universitas Muhammadiyah Prof. Dr. Hamka melalui Lembaga Pemberdayan dan Pengabdian Pada Masyarakat (LPPM) yang telah mendukung dalam bentuk pendanaan dan administrasi kegiatan pengabdian masyarakat di SMA UNISMU 1 Makasar.

2. Kepala Sekolah SMA UNISMU 1 Makasar yang telah membantu memberikan tempat dan fasilitas sehinggakegiatan pengabdian masyarakat berjalan lancer

3. Bapak-Ibu Guru SMA UNISMU 1 Makasar yang secara aktif menjadi peserta kegiatan.

\section{DAFTAR PUSTAKA}

Hartono. (2001). Pengembangan Pembelajaran Dengan Pendekatan Model-Model Pengajaran Sejarah. Semarang: PT. Prima Nugraha Pratama.

Irdana, N.,\& Kurnarawarman, S. (2018). Konsep Penataan Koleksi Museum untuk Mempermudah Pemahaman Wisatawan dalam Wisata Edukasi Arsip dan Koleksi Perbankan di Musesum Bank Mandiri Jakarta. Diplomatika, 1(2): 132-147.

Kushardjanto. (2015). Museum Nasional Indonesia. Jakarta: Museum Nasional Indonesia.

Mursidi, A. (2010). Pemanfaatan Museum Blambangan sebagai Sumber belajar Sejarah di Kelas X SMA Negeri Kabupaten Banyuwangi. Paramita, 20(2): 190-202. 
Nugroho, A., \& Mareza, L. (2016). Pemanfaatan Museum BRI dan Museum Jenderal Sudirman sebagai Sumber Belajar IPS oleh Siswa dan Guru SD di Purwokerto. Khazanah Pendidikan, 9(2).

Syafii. (2014). Museum sebagai Sumber Belajar dalam Upaya Pelestarian Ukir di Jepara: Sebuah Wacana. Imajinasi: Jurnal Seni, 7(1): 55-62.

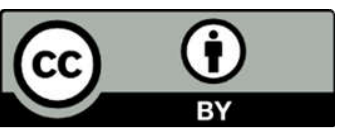

(C) 2018 Oleh authors. Lisensi Jurnal Solma, LPPM-UHAMKA, Jakarta. Artikel ini bersifat open access yang didistribusikan di bawah syarat dan ketentuan Creative Commons Attribution (CC BY) license (http://creativecommons.org/licenses/by/4.0/). 